\title{
Neonatal Effects of Magnesium Sulfate Given to the Mother
}

\author{
Mina Abbassi-Ghanavati, M.D. ${ }^{1}$ James M. Alexander, M.D. ${ }^{1}$ Donald D. McIntire, Ph.D. ${ }^{1}$ \\ Rashmin C. Savani, M.B.Ch.B. ${ }^{2}$ Kenneth J. Leveno, M.D. ${ }^{1}$
}

${ }^{1}$ Department of Obstetrics and Gynecology, University of Texas Southwestern Medical Center, Dallas, Texas

2 Department of Pediatrics, University of Texas Southwestern Medical Center, Dallas, Texas
Address for correspondence and reprint requests Kenneth J. Leveno, M.D., Department of Obstetrics and Gynecology, University of Texas Southwestern Medical Center at Dallas, 5323 Harry Hines Blvd., Dallas, TX 75390-9032 (e-mail: kenneth.leveno@utsouthwestern.edu).

\begin{abstract}
Keywords

- magnesium sulfate

- neuroprotection

- neonatal side effects

- neonatal hypotonia

- prevention of cerebral palsy

Objective Magnesium historically has been used for treatment and/or prevention of eclampsia or preterm labor. More recently, antepartum magnesium sulfate has been suggested for prevention of cerebral palsy in preterm infants. Although adverse effects and toxicity of magnesium in pregnant women are well known, the fetal-neonatal effects of magnesium are less clear. The objective of this study was to evaluate the effects of magnesium on the newborn infant.

Study Design This is a retrospective cohort analysis of women who received antepartum magnesium sulfate for prevention or treatment of eclampsia. Magnesium sulfate was given intravenously beginning with a $6-\mathrm{g}$ dose, followed by $2-\mathrm{to} 3-\mathrm{g} / \mathrm{h}$ infusion. Newborn hypotonia was diagnosed if an infant exhibited less than normal tone/ activity upon admission to the nursery.

Results Between January 2000 and February 2009, a total of 6654 women with preeclampsia were treated with intravenous magnesium sulfate as described; 88 (6\%) of the infants were diagnosed with hypotonia. Lower 1-minute and 5-minute Apgar scores, intubation in the delivery room, admission to special care nursery, and hypotonia were all significantly increased as maternal serum magnesium concentrations increased before birth.

Conclusion Several neonatal complications are significantly related to increasing concentrations of magnesium in the maternal circulation.
\end{abstract}

The history of obstetric use of magnesium sulfate begins with its use during the middle of the 20th century to treat and prevent eclampsia. Such use, however, was not generally accepted, particularly outside the United States, until relatively late in the century. ${ }^{1}$ About the same time, magnesium sulfate came to be increasingly used in an attempt to impede uterine contractions during preterm labor. Indeed, magnesium sulfate became the most commonly used tocolytic drug in the United States. ${ }^{2}$ Most recently, prevention of cerebral palsy in preterm infants has become another indication for administration of magnesium sulfate to the mother. ${ }^{3,4}$

It has long been known that magnesium ion can be toxic to the mother. For example, the patellar reflex disappears if the serum level reaches $\sim 8 \mathrm{mEq} / \mathrm{L}(4.0 \mathrm{mmol} / \mathrm{L})$ due to the noncompetitive antagonism of calcium ions by magnesium at the neuromuscular junction. ${ }^{5}$ This sign has been used to warn of impending magnesium toxicity because a further increase to 10 to $11 \mathrm{mEq} / \mathrm{L}$ ( 5.0 to $5.5 \mathrm{mmol} / \mathrm{L}$ ) leads to respiratory depression in the mother. The fetal-neonatal received

December 1, 2011

accepted after revision

March 13, 2012

published online

July 6, 2012
Copyright (c) 2012 by Thieme Medical Publishers, Inc., 333 Seventh Avenue, New York, NY 10001, USA. Tel: +1(212) 584-4662.
DOI http://dx.doi.org/ 10.1055/s-0032-1316440. ISSN 0735-1631. 
effects of magnesium ion given to the mother, however, are less clear, with very few reports in the medical literature. Early case reports suggested that magnesium ion given to the mother might induce neuromuscular blockade in the newborn infant and manifest as respiratory depression, hypotonia, and hyporeflexia., ${ }^{6,7}$ Based on subsequent small series, such neuromuscular effects in the newborn were found to have no clinical significance. ${ }^{8,9}$ Our purpose was to revisit these historical observations of the effects of magnesium ion on the newborn infant.

\section{Materials and Methods}

This is a retrospective cohort analysis of women who received magnesium sulfate $\cdot 7 \mathrm{H}_{2} \mathrm{O}$ for prevention or treatment of eclampsia at Parkland Hospital in Dallas, Texas. The obstetric service is staffed by faculty, house officers, fellows, and certified midwives under the aegis of the Department of Obstetrics and Gynecology at the University of Texas Southwestern Medical Center. Similarly, newborn and special care nurseries are staffed by faculty, house officers, fellows, and nurse practitioners from the Department of Pediatrics.

Obstetric and neonatal outcomes for women who deliver at Parkland are entered into a computerized database. Nurses present at delivery complete data sheets that are checked by research nurses for accuracy before electronic storage. Data on infant outcomes are abstracted from discharge records. This study was approved by Institutional Review Board of the University of Texas Southwestern Medical Center.

\section{Criteria for Diagnosis of Hypertensive Disorders Due to Pregnancy}

Our criteria for defining hypertensive disorders during pregnancy were those described in the Report of National High Blood Pressure Education Program Working Group on High Blood Pressure in Pregnancy (BP Working Group) and Practice Bulletin Number 33 of the American College of Obstetricians and Gynecologists. ${ }^{10,11}$ These include: (1) blood pressure of $140 / 90 \mathrm{~mm} \mathrm{Hg}$ or greater after 20 weeks' gestation in a woman not known to be chronically hypertensive and one or more of the following: (2) proteinuria of $2+$ or greater as measured by dipstick in a catheterized urine specimen, (3) serum creatinine more than $1.0 \mathrm{mg} / \mathrm{dL}$, (4) platelets less than $100,000 / \mu \mathrm{L},(5)$ aspartate transaminase elevated two times above upper limit of normal range, (6) persistent headache or scotomata, or (7) persistent midepigastic or right-upper quadrant pain.

\section{Administration of Magnesium Sulfate}

Magnesium sulfate infusions were given during labor and for 24 hours postpartum to women with hypertension with one or more of the items 2 to 7 in the criteria for diagnosis of hypertensive disorders. The infusion was commenced with a 6-g loading dose over 20 minutes, followed by $2 \mathrm{~g}$ per hour. Serum magnesium levels were measured 2 hours and 4 hours after the infusion started, with a goal of achieving a therapeutic range of 4 to $7 \mathrm{mEq} / \mathrm{L}$ (2.0 to $3.5 \mathrm{mmol} / \mathrm{L}$ ). The magnesium level was then routinely measured 12 hours after starting the infusion. In women whose serum magnesium level was less than $4.0 \mathrm{mEq} / \mathrm{L}(2.0 \mathrm{mmol} / \mathrm{L})$, the magnesium sulfate infusion was increased to $3 \mathrm{~g} / \mathrm{h}$. If the infusion rate was increased to $3 \mathrm{~g} / \mathrm{h}$, then a magnesium level was measured 4 hours after the increase. Magnesium levels were measured in the general hospital laboratories and reported in milliequivalents per liter (mEq/L). Magnesium sulfate infusions were not used for tocolysis nor neuroprotection against cerebral palsy.

\section{Infant Outcomes}

Infants included in this analysis were limited to live-born singletons without malformations delivered within 4 hours of a maternal serum magnesium level. Women given general anesthesia for cesarean delivery were excluded $(n=173)$. Apgar scores were assigned by labor and delivery nurses for uncomplicated births; all others were assigned by neonatology faculty, fellows, pediatric house officers, and neonatal nurse practitioners who were routinely present for all highrisk deliveries. Neonatal hypotonia was diagnosed at birth if the infant exhibited less than normal tone or activity on admission to the nursery. Intubation in the delivery room was at the discretion of attending pediatric personnel, usually a neonatology fellow. Intraventricular hemorrhage was graded according to the method of Papile and colleagues. ${ }^{12}$

\section{Statistical Analysis}

The association between magnesium level and categorical outcomes was analyzed using the Pearson chi-square and analysis of variance was used for continuous outcomes. Multivariable logistic regression was used to adjust gestational age at delivery, length of labor, and nulliparity. The data were analyzed using SAS, version 9.2 (SAS Institute, Cary, NC). Two-sided $p$ values less than 0.05 were considered significant.

\section{Results}

Between January 1, 2000, and February 1, 2009, a total of 144,715 women were delivered at Parkland Hospital; 7374 women were given magnesium sulfate $\cdot 7 \mathrm{H}_{2} \mathrm{O}$ for intrapartum management of pregnancy hypertension, and 6654 (90\%) met inclusion criteria for this analysis.

\section{Serum Magnesium Levels}

The distribution of maternal serum magnesium concentrations, duration of magnesium sulfate infusion, as well as the mean number of magnesium levels measured are shown in - Table 1. The duration of infusion and number of magnesium levels measured were both significantly related to the serum magnesium level in the mother. That is, higher levels were associated with longer infusions. A total of 139 women had magnesium levels $7.0 \mathrm{mEq} / \mathrm{L}$ (3.5 mmol/L) or greater; their mean concentration was $7.7 \pm 0.7 \mathrm{mEq} / \mathrm{L}(3.8 \pm 0.35$ $\mathrm{mmol} / \mathrm{L}$ ) with a range of 7.1 to $11.0 \mathrm{mEq} / \mathrm{L}$ (3.6 to $5.5 \mathrm{mmol} / \mathrm{L}$ ).

\section{Maternal Demographics}

Maternal demographic characteristics for the study cohort are shown in - Table $\mathbf{2}$. The majority of the women were 
Table 1 Maternal Serum Magnesium Levels within 4 Hours of Delivery in 6654 Women as Well as Infusion Times and Number of Serum Levels Measured

\begin{tabular}{|c|c|c|c|c|c|c|c|}
\hline \multicolumn{8}{|c|}{ Magnesium Level (mEq/L) } \\
\hline Outcome & $\begin{array}{l}0-3.0 \\
(n=326)\end{array}$ & $\begin{array}{l}3.0-3.99 \\
(n=1965)\end{array}$ & $\begin{array}{l}4.0-4.99 \\
(n=2572)\end{array}$ & $\begin{array}{l}5.0-5.99 \\
(n=1329)\end{array}$ & $\begin{array}{l}6.0-6.99 \\
(n=323)\end{array}$ & $\begin{array}{l}7.0 \text { or Greater } \\
(n=139)\end{array}$ & $p$ Value \\
\hline Infusion hours & $3.8 \pm 4.1$ & $4.1 \pm 3.4$ & $8.4 \pm 5.1$ & $13.1 \pm 6.1$ & $15.7 \pm 6.1$ & $19.1 \pm 6.7$ & $<0.001$ \\
\hline No. magnesium levels & $1.5 \pm 0.8$ & $1.8 \pm 0.9$ & $2.7 \pm 1.1$ & $3.6 \pm 1.3$ & $4.0 \pm 1.2$ & $4.5 \pm 1.3$ & $<0.001$ \\
\hline
\end{tabular}

All data shown as mean \pm standard deviation. $1 \mathrm{mEq} / \mathrm{L}=2 \mathrm{mmol} / \mathrm{L}$.

Hispanic, reflecting the general obstetric population at Parkland Hospital. Few women were in groups at the extremes of reproductive age, and more than half were nulliparous or obese. These demographic characteristics were analyzed in relation to maternal serum magnesium levels, and race/ ethnicity, age, and nulliparity were all significantly associated with higher magnesium levels. Further analysis using logistic regression showed nulliparity was a factor likely due to longer labors and hence greater exposure to magnesium sulfate infusion. Maternal serum magnesium levels were inversely proportional to body mass index, which reflects the volume of distribution for magnesium ion.

\section{Neonatal Outcomes in Relation to Maternal Serum Magnesium Levels}

A variety of neonatal outcomes are shown in - Table 3 in relation to maternal serum magnesium concentrations. Gestational age at delivery, mechanical ventilation in the nursery, intraventricular hemorrhage, and neonatal death

Table 2 Maternal Demographic Characteristics in Women with Pregnancy Hypertension and Treated with Magnesium Sulfate Infusions

\begin{tabular}{|c|c|}
\hline Characteristic & $\begin{array}{l}\text { Number of Women } \\
(n=6654)\end{array}$ \\
\hline \multicolumn{2}{|l|}{ Race/ethnicity } \\
\hline Hispanic & $5217(78)$ \\
\hline African-American & $1063(16)$ \\
\hline White & $286(4)$ \\
\hline Other & $88(1)$ \\
\hline \multicolumn{2}{|l|}{ Age $(y)$} \\
\hline$\leq 15$ & $138(2)$ \\
\hline $16-34$ & $5770(87)$ \\
\hline$\geq 35$ & $746(11)$ \\
\hline Nulliparity & $3580(54)$ \\
\hline \multicolumn{2}{|l|}{ Body mass index ${ }^{a}$} \\
\hline$\leq 19$ & $3(-)$ \\
\hline $20-24$ & $328(5)$ \\
\hline $25-30$ & $1533(23)$ \\
\hline$>30$ & $4254(63)$ \\
\hline
\end{tabular}

All data shown as $n(\%)$.

${ }^{\mathrm{a}}$ Data missing in $536(8 \%)$ women. were not significantly associated with maternal serum magnesium concentrations. In contrast, 1-minute and 5-minute Apgar scores, intubation in the delivery room, admission to special care nursery, and hypotonia were significantly increased as maternal serum magnesium concentrations increased. For example, $12 \%$ of infants whose mothers had magnesium levels $7.0 \mathrm{mEq} / \mathrm{L}$ (3.5 mmol/L) or greater had hypotonia compared with $3 \%$ in those with levels of 3.0 to $3.99 \mathrm{mEq} / \mathrm{L}$ ( 1.5 to $2.0 \mathrm{mmol} / \mathrm{L}, p<0.001$ ). Similarly, intubation in the delivery room occurred in $5 \%$ of infants born to mothers with magnesium levels $7.0 \mathrm{mEq} / \mathrm{L}(3.5 \mathrm{mmol} / \mathrm{L})$ or greater compared with $2 \%$ in women with levels 3.0 to $3.99 \mathrm{mEq} / \mathrm{L}$ ( 1.5 to $2.0 \mathrm{mmol} / \mathrm{L}, p<0.001$ ). Logistic regression analysis, adjusting for nulliparity, gestational age at birth, and length of labor was performed for hypotonia and intubation in the delivery room. As shown in - Fig. 1, the rate of hypotonia was proportional to the maternal serum magnesium level. After adjustment, intubation in the delivery room was significantly associated with maternal magnesium serum levels exceeding $7.0 \mathrm{mEq} / \mathrm{L}$ (3.5 mmol/L; odds ratio 4.6, 95\% confidence interval 1.4 to 15.4 ).

\section{Discussion}

Our analysis indicates that several neonatal outcomes are significantly related to increasing concentrations of magnesium ion in the maternal circulation. Apgar scores, hypotonia, intubation in the delivery room, and admission to a special care nursery were all increased as the maternal magnesium level increased from 3.0 to $7.0 \mathrm{mEq} / \mathrm{L}$ ( 1.5 to $3.5 \mathrm{mmol} / \mathrm{L}$ ) or greater. The great preponderance of maternal magnesium levels were in the desired therapeutic range of 4.0 to $7.0 \mathrm{mEq} / \mathrm{L}$ (2.0 to $3.5 \mathrm{mmol} / \mathrm{L})$; only 33 women $(0.5 \%$ of the study cohort) had levels exceeding $8 \mathrm{mEq} / \mathrm{L}(4.0 \mathrm{mmol} / \mathrm{L})$ and the highest level was $9.1 \mathrm{mEq} / \mathrm{L}(4.6 \mathrm{mmol} / \mathrm{L})$. That is, the neonatal effects of magnesium ion that we observed occurred primarily within the therapeutic range and were not solely attributable to excessive levels of magnesium in the maternal circulation. Although there were several adverse neonatal effects of magnesium sulfate, it is likely that their clinical impact was small because neonatal death and serious morbidities such as need for significant respiratory support in the nursery were not statistically related to maternal magnesium levels. However, we believe that larger prospective trials would be necessary to more completely evaluate the potential adverse effects of neonatal hypermagnesemia. 
Table 3 Selected Neonatal Outcomes in Relation to Maternal Magnesium Levels Measured within 4 Hours of Birth

\begin{tabular}{|c|c|c|c|c|c|c|c|}
\hline \multicolumn{8}{|c|}{ Magnesium Level (mEq/L) } \\
\hline & $\begin{array}{l}0-3.0 \\
(n=326)\end{array}$ & $\begin{array}{l}3.0-3.99 \\
(n=1965)\end{array}$ & $\begin{array}{l}4.0-4.99 \\
(n=2572)\end{array}$ & $\begin{array}{l}5.0-5.99 \\
(n=1329)\end{array}$ & $\begin{array}{l}6.0-6.99 \\
(n=323)\end{array}$ & $\begin{array}{l}7.0 \text { or Greater } \\
(n=139)\end{array}$ & $p$ Value \\
\hline \multicolumn{8}{|l|}{ Outcome } \\
\hline Gestational age (wk) & & & & & & & 0.173 \\
\hline $24-27$ & $4(1.2)$ & $9(0.5)$ & $11(0.4)$ & $5(0.4)$ & $1(0.3)$ & $1(0.7)$ & \\
\hline $28-33$ & $20(6.1)$ & $124(6.3)$ & $144(5.6)$ & $77(5.8)$ & $17(5.3)$ & $4(2.9)$ & \\
\hline $34-36$ & $54(16.6)$ & $230(11.7)$ & $352(13.7)$ & $175(13.2)$ & $39(12.1)$ & $11(7.9)$ & \\
\hline$\geq 37$ & $248(76.1)$ & $1602(81.5)$ & $2065(80.3)$ & $1072(80.7)$ & $266(82.4)$ & $123(88.5)$ & \\
\hline \multicolumn{8}{|l|}{ 1-min Apgar } \\
\hline Mean \pm SD & $7.8 \pm 1.6$ & $8.0 \pm 1.4$ & $7.9 \pm 1.5$ & $7.7 \pm 1.6$ & $7.4 \pm 1.9$ & $6.9 \pm 2.3$ & $<0.001$ \\
\hline$\leq 3$ & $13(4)$ & $49(2)$ & $95(4)$ & $51(4)$ & $21(7)$ & $17(12)$ & $<0.001$ \\
\hline \multicolumn{8}{|l|}{ 5-min Apgar } \\
\hline Mean \pm SD & $8.8 \pm 0.6$ & $8.8 \pm 0.6$ & $8.8 \pm 0.6$ & $8.8 \pm 0.7$ & $8.6 \pm 1.0$ & $8.5 \pm 0.9$ & $<0.001$ \\
\hline$\leq 3$ & $0(0)$ & $3(0.2)$ & $5(0.2)$ & $1(0.1)$ & $3(0.9)$ & $0(0)$ & 0.779 \\
\hline $\begin{array}{l}\text { Intubation in } \\
\text { delivery room }\end{array}$ & $9(3)$ & $36(2)$ & $46(2)$ & $14(1)$ & $6(2)$ & $7(5)$ & 0.003 \\
\hline Special care nursery & $78(24)$ & $342(17)$ & 491 (19) & $279(21)$ & $80(25)$ & $34(24)$ & $<0.001$ \\
\hline Hypotonia & $12(4)$ & $56(3)$ & $135(5)$ & $112(8)$ & $40(12)$ & $18(13)$ & $<0.001$ \\
\hline $\begin{array}{l}\text { Significant respiratory } \\
\text { support in the nurserya }\end{array}$ & $40(12)$ & $163(8)$ & $195(8)$ & $95(7)$ & $29(9)$ & $10(7)$ & 0.30 \\
\hline \multicolumn{8}{|c|}{ Intraventricular hemorrhage } \\
\hline Any grade & $7(2)$ & $37(2)$ & $29(1)$ & $23(2)$ & $7(2)$ & $0(0)$ & 0.25 \\
\hline Grades III/IV & $1(0.3)$ & $3(0.2)$ & $2(0.1)$ & $2(0.2)$ & $1(0.3)$ & $0(0)$ & 0.96 \\
\hline Neonatal death & $0(0)$ & $1(0.1)$ & $6(0.2)$ & $1(0.1)$ & $0(0)$ & $0(0)$ & 0.62 \\
\hline
\end{tabular}

All data shown as $n(\%)$ or mean \pm SD. $1 \mathrm{mEq} / \mathrm{L}=2 \mathrm{mmol} / \mathrm{L}$. SD, standard deviation.

ancludes intubation or continuous positive airway pressure in the special care nursery.

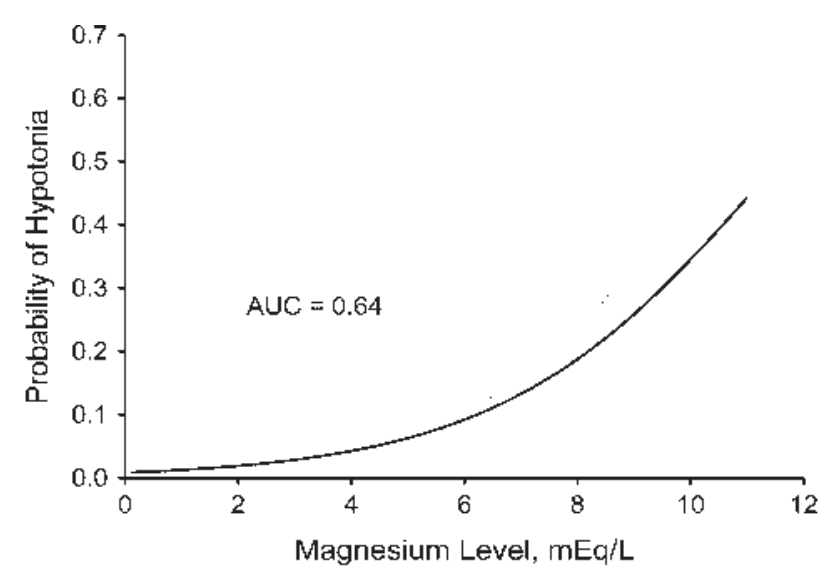

AUC = area under curve

$1 \mathrm{mEq} / \mathrm{L}=2 \mathrm{mmol} \cdot \mathrm{L}$

Figure 1 Probability of neonatal hypotonia in relation to maternal serum magnesium concentrations measured within 4 hours of birth. Data adjusted for gestational age, nulliparity, and length of labor. The $p$ value for association of hypotonia and magnesium level is $<0.001$. AUC, area under the curve.
Our findings of adverse neonatal effects of magnesium sulfate given to the mother are not new. Indeed, Lipsitz and English ${ }^{6}$ reported more than 40 years ago a case series of six infants who had hyporeflexia, hypotonia, and respiratory depression, which was attributed to magnesium sulfate given to the mother. Lipsitz later reported a larger case series including 37 infants in which he found a trend toward lower Apgar scores in association with maternal magnesium sulfate therapy. ${ }^{13}$ Stone and Pritchard ${ }^{14}$ were unable to confirm changes in Apgar scores in 118 infants born of women given magnesium sulfate for prevention of eclampsia. Donovan and colleagues ${ }^{15}$ reported decreased muscle tone in 20 newborn infants associated with maternal magnesium levels. Chesley ${ }^{16}$ found cord blood magnesium levels to be 70 to $96 \%$ of those in the mother with a progressive increase in fetal levels as the duration of maternal magnesium sulfate therapy lengthened. Until very recently, the literature now cited comprised most of the information on the neonatal effects of magnesium sulfate given to the mother. In 2008, Rouse and colleagues ${ }^{3}$ randomized magnesium sulfate infusions or placebo in 2241 women delivered between 24 and 31 weeks' gestation in a study of the effects of magnesium sulfate on 
perinatal death and/or cerebral palsy at 2 years of age. Magnesium sulfate therapy was not found to be associated with perinatal death, neonatal hypotonia, or any other neonatal morbidities. Such therapy, however, was associated with a significant reduction in cerebral palsy, especially in infants born between 24 and 27 weeks' gestation.

The increasing, almost ubiquitous use of magnesium sulfate in American obstetrics has not occurred without concerns as to the safety of magnesium sulfate infusions. For example, the Institute of Medicine ${ }^{17}$ as well as the Joint Commission on Accreditation of Healthcare Organizations have identified magnesium sulfate as a high-risk medication for pregnant women. Indeed, magnesium sulfate is listed as a "High Alert Medication" by the Institution for Safe Medication Practices. ${ }^{18}$ Although recognized as a high-risk medication, the number of maternal adverse drug events is not well documented in the United States. Simpson and Knox, in the span of few years, accumulated 52 cases of accidental maternal overdosage with magnesium sulfate. ${ }^{19}$ Clearly, magnesium sulfate infusions pose risks to the pregnant woman. Our results, showing neonatal effects and confirming largely forgotten observations made more than 40 years ago, lead us to conclude that administration of magnesium sulfate to pregnant women has discernible effects on the newborn infant.

\section{References}

1 Belfort MA, Anthony J, Saade GR, Allen JC Jr; Nimodipine Study Group. A comparison of magnesium sulfate and nimodipine for the prevention of eclampsia. N Engl J Med 2003;348:304-311

2 Grimes DA, Nanda K. Magnesium sulfate tocolysis: time to quit. Obstet Gynecol 2006;108:986-989

3 Rouse DJ, Hirtz DG, Thom E, et al; Eunice Kennedy Shriver NICHD Maternal-Fetal Medicine Units Network. A randomized, controlled trial of magnesium sulfate for the prevention of cerebral palsy. $\mathrm{N}$ Engl J Med 2008;359:895-905

4 American College of Obstetricians and Gynecologists Committee on Obstetric Practice; Society for Maternal-Fetal Medicine. Committee Opinion No. 455: Magnesium sulfate before anticipated preterm birth for neuroprotection. Obstet Gynecol 2010;115: 669-671

5 Pearson HA, Wray D. Non-competitive antagonism of calcium by magnesium ions at the $\mathrm{K}(+)$-depolarised mouse neuromuscular junction. Eur J Pharmacol 1993;236:323-326

6 Lipsitz PJ, English IC. Hypermagnesemia in the newborn infant. Pediatrics 1967;40:856-862

7 Rasch DK, Huber PA, Richardson CJ, L'Hommedieu CS, Nelson TE, Reddi R. Neurobehavioral effects of neonatal hypermagnesemia. J Pediatr 1982;100:272-276

8 Green KW, Key TC, Coen R, Resnik R. The effects of maternally administered magnesium sulfate on the neonate. Am J Obstet Gynecol 1983;146:29-33

9 Riaz M, Porat R, Brodsky NL, Hurt H. The effects of maternal magnesium sulfate treatment on newborns: a prospective controlled study. J Perinatol 1998;18(6 Pt 1):449-454

10 National High Blood Pressure Education Program Working Group. Report of the National High Blood Pressure Education Program Working Group on High Blood Pressure in Pregnancy. Am J Obstet Gynecol 2000;183:S1-S22

11 ACOG Committee on Practice Bulletins-Obstetrics. ACOG practice bulletin. Diagnosis and management of preeclampsia and eclampsia. Number 33, January 2002. Obstet Gynecol 2002;99:159-167

12 Papile LA, Burstein J, Burstein R, Koffler H. Incidence and evolution of subependymal and intraventricular hemorrhage: a study of infants with birth weights less than 1,500 gm. J Pediatr 1978;92: 529-534

13 Lipsitz PJ. The clinical and biochemical effects of excess magnesium in the newborn. Pediatrics 1971;47:501-509

14 Stone SR, Pritchard JA. Effect of maternally administered magnesium sulfate on the neonate. Obstet Gynecol 1970;35:574-577

15 Donovan EF, Tsang RC, Steichen JJ, Strub RJ, Chen IW, Chen M. Neonatal hypermagnesemia: effect on parathyroid hormone and calcium homeostasis. J Pediatr 1980;96:305-310

16 Chesley LC. Hypertensive Disorders in Pregnancy. New York: Appleton-Century-Crofts; 1978

17 Kohn LT, Corrigan JM, Donaldson MS, eds. To Err Is Human: Building a Safer Health System. Washington, DC: Institute of Medicine and the National Academy Press; 1999

18 The Institution for Safe Medication Practices List of High Alert Medication. http://www.ismp.org/Tools/highalertmedications.pdf. Accessed June 5, 2012

19 Simpson KR, Knox GE. Obstetrical accidents involving intravenous magnesium sulfate: recommendations to promote patient safety. MCN Am J Matern Child Nurs 2004;29:161-169; quiz $170-171$ 